\title{
Prognostic significance of peripheral monocyte count in patients with extranodal natural killer/T-cell lymphoma
}

\author{
Jia-Jia Huang ${ }^{1,2}$, Ya-Jun Li ${ }^{1,2}$, Yi Xia ${ }^{1,2}$, Yu Wang ${ }^{1,2}$, Wen-Xiao Wei ${ }^{1,2}$, Ying-Jie Zhu ${ }^{1,2}$, Tong-Yu Lin ${ }^{1,2}$,
} Hui-Qiang Huang ${ }^{1,2}$, Wen-Qi Jiang ${ }^{1,2}$ and Zhi-Ming Li $i^{1,2^{*}}$

\begin{abstract}
Background: Extranodal natural killer/T-cell lymphoma (ENKL) has heterogeneous clinical manifestations and prognosis. This study aims to evaluate the prognostic impact of absolute monocyte count (AMC) in ENKL, and provide some immunologically relevant information for better risk stratification in patients with ENKL.

Methods: Retrospective data from 163 patients newly diagnosed with ENKL were analyzed. The absolute monocyte count (AMC) at diagnosis was analyzed as continuous and dichotomized variables. Independent prognostic factors of survival were determined by Cox regression analysis.

Results: The AMC at diagnosis were related to overall survival (OS) and progression-free survival (PFS) in patients with ENKL. Multivariate analysis identified AMC as independent prognostic factors of survival, independent of International Prognostic Index (IPI) and Korean prognostic index (KPI). The prognostic index incorporating AMC and absolute lymphocyte count (ALC), another surrogate factor of immune status, could be used to stratify all 163 patients with ENKL into different prognostic groups. For patients who received chemotherapy followed by radiotherapy (102 cases), the three AMC/ALC index categories identified patients with significantly different survivals. When superimposed on IPI or KPI categories, the AMC/ALC index was better able to identify high-risk patients in the low-risk IPI or KPI category.
\end{abstract}

Conclusion: The baseline peripheral monocyte count is shown to be an effective prognostic indicator of survival in ENKL patients. The prognostic index related to tumor microenvironment might be helpful to identify high-risk patients with ENKL.

Keywords: Absolute monocyte count, Extranodal natural killer/T-cell lymphoma, Prognosis, Tumor microenvironment

\section{Background}

Extranodal nasal-type natural killer/T-cell lymphoma (ENKL) is a rare lymphoid neoplasm characterized by a cytotoxic phenotype. It is associated with Epstein-Barr virus (EBV) infection, vascular destruction, and obvious necrosis [1,2]. Its incidence is low in western populations but more prevalent in Latin America and East Asia, including China [3-5]. ENKL in China accounts for approximately $5-16 \%$ of all lymphoid neoplasms [5-8]. Patients

\footnotetext{
* Correspondence: Izmlzmlzm@yahoo.com

${ }^{1}$ State Key Laboratory of Oncology in South China, Guangzhou, China

${ }^{2}$ Department of Medical Oncology, Sun Yat-sen University Cancer Center, 651 Dong Feng RD East, Guangzhou 510060, China
}

with ENKL have heterogeneous clinical manifestations and prognosis $[9,10]$. Using the International Prognostic Index (IPI), nearly $80 \%$ of ENKL cases were categorized as low-risk, although some patients in this category have a poor prognosis [11]. Therefore, more and more studies are trying to find novel prognostic markers or another index, such as the Korean prognostic index (KPI), to better stratify patients with ENKL based on risk [12].

Immune system deficiency is a risk factor for nonHodgkin lymphomas (NHL) [13,14]. Gene-expression profiling studies show an interaction between the host immune system and lymphoma [15-17]. Lymphopenia, a surrogate factor of immune status, is reported to be an 
unfavorable prognostic factor for leukemia, B-cell neoplasms [18-22]. In the recent preclinical studies, monocytes are found to be plentiful in the tumor microenvironment and contribute to the growth of malignant T-cells [23]. Monocytes have also been found to induce the proliferation of natural killer (NK)/T lymphoma cells and to infiltrate lymphomas [24]. Recent evidence shows a relationship between peripheral monocyte count (another immunologically relevant marker) and survival in patients with diffuse large B-cell lymphoma (DLBCL) and follicular lymphoma (FL) $[25,26]$. To the best of our knowledge, the prognostic impact of absolute monocyte count (AMC) in NK/T cell lymphoma has never been assessed. The current study was performed to investigate the prognostic influence of monocytes (another surrogate marker for tumor microenvironment) on survival in ENKL, and provide some information on host immunity at diagnosis for better risk stratification in patients with ENKL.

\section{Methods}

\section{Ethics statement}

This study was approved by the Institutional Review Board (IRB) of Sun Yat-Sen University Cancer Center. Study was performed in accord with the principles of the Declaration of Helsinki. All patients agreed to use their medical records for research.

\section{Patients and staging}

This retrospective study included 163 patients with ENKL newly diagnosed between January 2001 and December 2009 at the Sun Yat-Sen University Cancer Center of China. All the cases were pathologically confirmed as extranodal NK/T-cell lymphoma, nasal type, based on morphologic and immunophenotypic criteria of the 2001 World Health Organization (WHO) classification. Cases with blastic NKcell lymphoma/leukemia, aggressive NK-cell lymphoma/ leukemia, peripheral T-cell lymphoma, unspecified, or with negative EBV in situ hybridization, were excluded. Informed consent was obtained from all patients prior to treatment.

Information regarding demographics, Eastern Cooperative Oncology Group (ECOG) performance status, physical examinations, systemic B symptoms, complete blood count $(\mathrm{CBC})$, biochemical profiles, and serum lactate dehydrogenase (LDH) level were collected for analysis. The staging was based on the Ann Arbor staging system. Whole-body positron emission tomography/computed tomography (PET/CT) scans, CT scans or magnetic resonance imaging (MRI) scans of the involved sites, as well as thorax, abdomen, and pelvic CT scans, and bone marrow findings were used for staging. Patients with contiguous involvement extending to the adjacent tissues or organs were regarded as stage IE. Upper aerodigestive tract NK/T-cell lymphoma (UNKTL) and extra- upper aerodigestive tract NK/T-cell lymphoma (EUNKTL) were defined as previously described [8,27]. The International Prognostic Index (IPI: stage, ECOG performance status, serum LDH, stage, extranodal sites) and the Korean Prognostic Index for NK/ T-cell lymphoma with nasal disease (KPI: serum LDH level, B symptoms, stage, regional lymph nodes involvement) were evaluated as previously described [12,28].

\section{Treatment modalities and response criteria}

Patients received one of the following treatments: (i) chemotherapy followed by radiotherapy; (ii) chemotherapy alone; (iii) involved-field radiation alone; (iv) surgery followed by radiation; (v) best supportive care. The firstline chemotherapy regimens were: EPOCH (etoposide,

\section{Table 1 Clinical characteristics of 163 patients with extranodal nasal-type natural killer/T-cell lymphoma (ENKL) at diagnosis}

\begin{tabular}{|c|c|c|}
\hline Characteristics & Number of patients & $\%$ \\
\hline Age, median y (range) & $43(17-80)$ & \\
\hline \multicolumn{3}{|l|}{ Sex } \\
\hline Male & 113 & 69.3 \\
\hline Female & 50 & 30.7 \\
\hline \multicolumn{3}{|l|}{ ECOG score } \\
\hline $0-1$ & 151 & 92.6 \\
\hline$\geq 2$ & 12 & 7.4 \\
\hline Serum LDH > $245 \mathrm{u} / \mathrm{l}$ & 55 & 33.7 \\
\hline B symptoms & 85 & 52.1 \\
\hline Extranodal sites of involvement $\geq 2$ & 23 & 14.1 \\
\hline \multicolumn{3}{|l|}{ Ann Arbor Stage } \\
\hline$|-| \mid$ & 128 & 78.5 \\
\hline III-IV & 35 & 21.5 \\
\hline \multicolumn{3}{|l|}{ Subtype } \\
\hline UNKTL & 140 & 85.9 \\
\hline EUNKTL & 23 & 14.1 \\
\hline Regional lymph node involvement ${ }^{\mathrm{a}}$ & 53 & 38.4 \\
\hline \multicolumn{3}{|l|}{ KPI score ${ }^{b}$} \\
\hline $0-1$ & 84 & 60.9 \\
\hline $2-4$ & 54 & 39.1 \\
\hline \multicolumn{3}{|l|}{ IPI score } \\
\hline $0-1$ & 125 & 76.7 \\
\hline $2-5$ & 38 & 23.3 \\
\hline $\mathrm{AMC} \geq 0.50 \times 10^{9} / \mathrm{L}$ & 118 & 72.4 \\
\hline
\end{tabular}

Abbreviations: ECOG PS, Eastern Cooperative Oncology Group performance status; LDH, lactate dehydrogenase; UNKTL, upper aerodigestive tract NK/T-cell lymphoma; EUNKTL, extraupper aerodigestive tract NK/T-cell lymphoma; KPI, Korean Prognostic Index; IPI, International Prognostic Index; AMC, absolute monocyte count.

${ }^{a}$ Complete data on regional lymph node involvement was available in 138 patients.

${ }^{\mathrm{b}}$ Complete data on KPI prognostic score was assessable in 138 patients. 

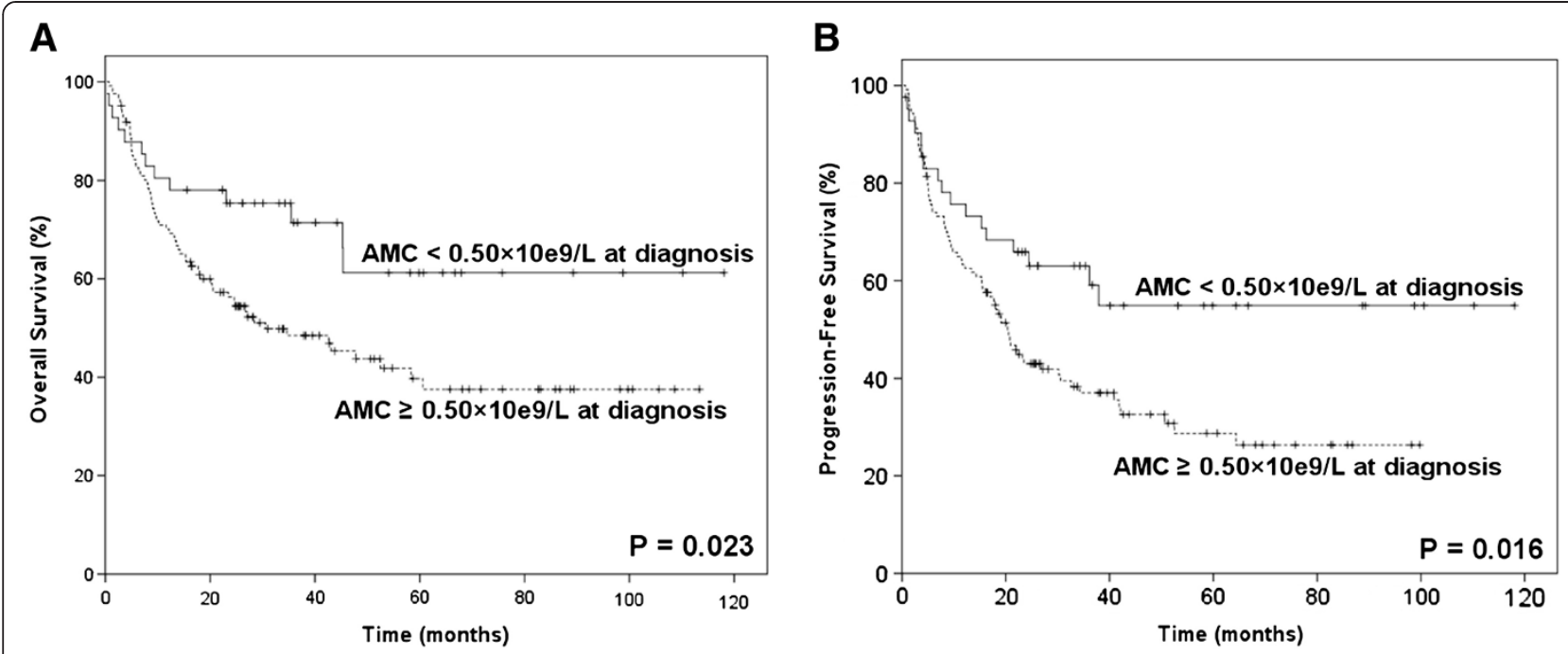

Figure 1 Survivals in ENKL stratified by AMC. Overall survival (A) and progression-free survival (B) of all patients ( $n=163)$ with ENKL stratified by the absolute monocyte count $\left(\geq 0.50 \times 10^{9} / \mathrm{L}\right.$ versus $\left.<0.50 \times 10^{9} / \mathrm{L}\right)$ at diagnosis.

doxorubicin, vincristine, cyclophosphamide, prednisone), $\mathrm{CHOP}$ (cyclophosphamide, doxorubicin, vincristine, and prednisone) or CHOP-like therapy, alternating triple therapy (CHOP-B [cyclophosphamide, doxorubicin, vincristine, prednisone, bleomycin], IMVP-16 [ifosfamide, etoposide, methotrexate], and DHAP [dexamethasone, cytarabine, cisplatin]), GEMOX (gemcitabine, oxaliplatin) +/- L-asparaginase, and SMILE (dexamethasone, methotrexate, ifosfamide, L-asparaginase, etoposide). Radiotherapy for the involved-field was given in daily fractions of 2 Gy (five fractions per week) for a total of 36-68 Gy. The International Working Group Recommendations for Response Criteria for non-Hodgkin's lymphoma were used to evaluate the treatment response [29].

\section{Statistical analysis}

Overall survival (OS) and progression-free survival (PFS) were assessed by the Kaplan-Meier method. OS was calculated from the date of diagnosis to the date of death from any cause, or date of the last follow-up. PFS was calculated from the date of diagnosis to the date of first

Table 2 Multivariate Cox-regression analysis of variables related to overall survival in patients with extranodal nasal-type natural killer/T-cell lymphoma $(n=163)$

\begin{tabular}{cccc}
\hline Variables & Hazard ratio (HR) & 95\% Confidence index (CI) & $\boldsymbol{P}$ \\
\hline $\mathrm{AMC} \geq$ & 2.124 & $1.141-3.956$ & 0.018 \\
$0.50 \times 10^{9} / \mathrm{L}$ & & & \\
$\mathrm{IPI}$ score & 2.197 & $1.415-3.409$ & $<0.001$ \\
\hline
\end{tabular}

Abbreviations: AMC, absolute monocyte count; IPI, International Prognostic Index. lymphoma progression, death from any cause, or date of the last follow-up [29]. The absolute monocyte count (AMC) at diagnosis was analyzed as both continuous and dichotomized parameters. The optimal cut-off values of the $\mathrm{AMC}$ were determined using the receiver operating characteristics (ROC) method. In the ROC curve analysis, survival outcomes were dichotomized into death versus survival. The relationship between AMC (as a dichotomized variable) and clinical parameters was analyzed by Pearson's $\chi 2$ test. Survival curves were constructed using the Kaplan-Meier method. The prognostic influence of different parameters on survival was established by multivariate analysis using the Cox proportional hazards model. The two-tailed log-rank test method was used to determined statistical difference, and $P$ value of less than 0.05 was regarded as statistically significant. Statistical analysis was carried out by SPSS 16.0 software.

\section{Results}

\section{Patients characteristics}

The baseline characteristics of all 163 patients with ENKL are shown in Table 1. The median age at the time of

Table 3 Multivariate Cox-regression analysis of variables related to progression-free survival in patients with extranodal nasal-type natural killer/T-cell lymphoma $(n=163)$

\begin{tabular}{cccc}
\hline Variables & Hazard ratio (HR) & $\begin{array}{c}\text { 95\% Confidence } \\
\text { index }(\mathrm{Cl})\end{array}$ & $\boldsymbol{P}$ \\
\hline $\mathrm{AMC} \geq$ & 1.906 & $1.127-3.223$ & 0.016 \\
$0.50 \times 10^{9} / \mathrm{L}$ & 1.728 & $1.163-2.568$ & 0.007 \\
$\mathrm{IPI}$ score & & & \\
\hline
\end{tabular}

Abbreviations: AMC, absolute monocyte count; IPI, International Prognostic Index. 

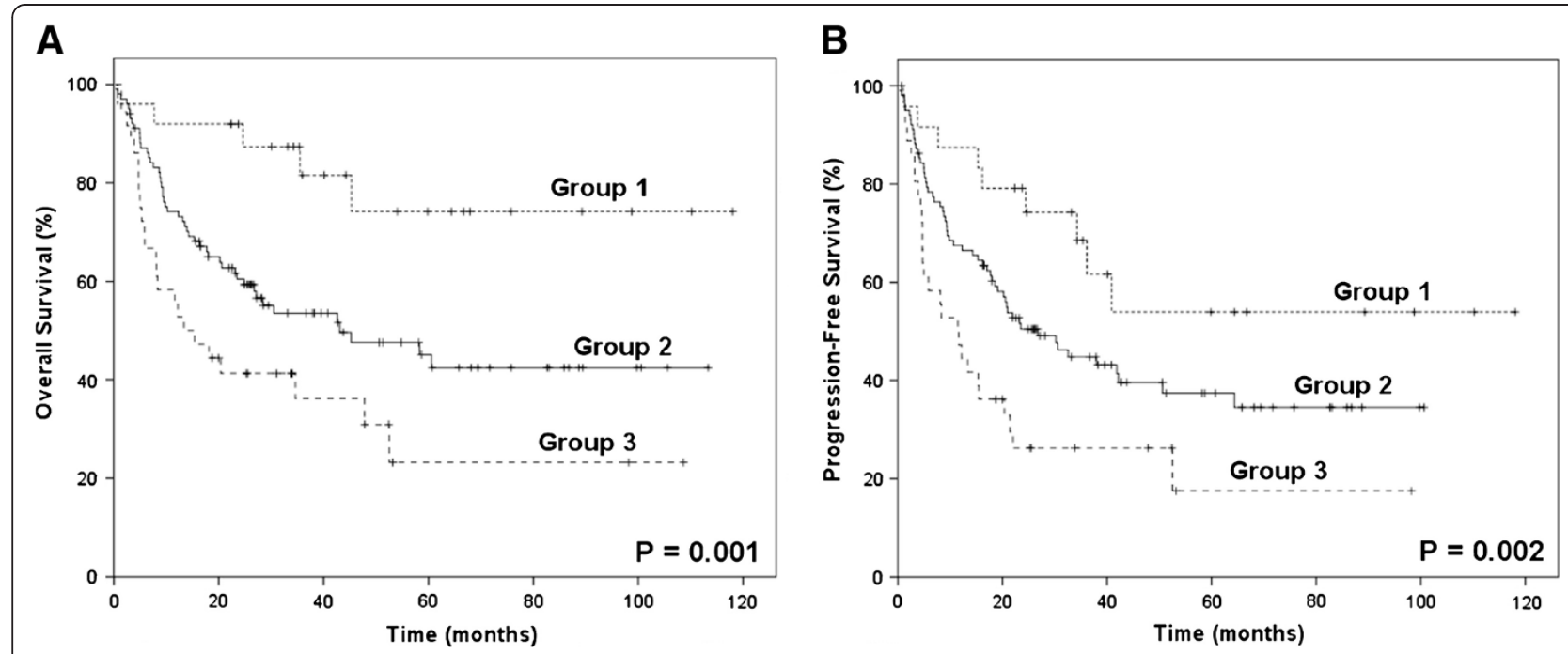

Figure 2 Survivals in ENKL categorized by the prognostic index. Overall survival (A) and progression-free survival (B) of all patients ( $\mathrm{n}=163$ ) with ENKL categorized by the absolute monocyte and lymphocyte prognostic index. Group 1 (low risk), AMC $<0.50 \times 10^{9} / \mathrm{L}$ and $\mathrm{ALC}>1.10 \times 10^{9} / \mathrm{L}$; Group 2 (intermediate risk), $\mathrm{AMC} \geq 0.50 \times 10^{9} / \mathrm{L}$ or $\mathrm{ALC} \leq 1.10 \times 10^{9} / \mathrm{L}$; Group 3 (high risk), AMC $\geq 0.50 \times 10^{9} / \mathrm{L}$ and $\mathrm{ALC} \leq 1.10 \times 10^{9} / \mathrm{L}$.

diagnosis was 43 years (range: 17-80). There was a male predominance (113 men and 50 women). Eight-five patients $(52.1 \%)$ presented systemic B symptoms, and 55 patients $(33.7 \%)$ had elevated serum LDH level prior to treatment. Nearly $80 \%$ of the patients (128 cases) had localized disease (Ann Arbor stage: I-II). Upper aerodigestive tract NK/T-cell lymphoma (UNKTL) was diagnosed in 140 cases $(85.9 \%)$ and extra-upper aerodigestive tract NK/T-cell lymphoma (EUNKTL) in 23 cases (14.1\%). For those with EUNKTL, the most common sites of primary extranodal involvement were cutaneous or soft tissue (11 cases), followed by the gastrointestinal tract ( 5 cases). International
Prognostic Index (IPI) assessment found that the majority of the patients (125 cases, 76.7\%) were in the low-risk category (IPI score $=0-1$ ). The Korean Prognostic Index (KPI) was assessable in 138 patients with nasal disease. In the KPI model, 84 patients $(60.9 \%)$ had no or one adverse factor, and the remaining 54 patients $(39.1 \%)$ had at least two adverse factors.

The AMC were obtained from the complete blood count $(\mathrm{CBC})$ test prior to treatment. The median AMC at diagnosis, range, and the $25 \%$ and $75 \%$ quartiles were $0.60 \times 10^{9} / \mathrm{L}, 0.05-2.10 \times 10^{9} / \mathrm{L}, 0.44 \times 10^{9} / \mathrm{L}$, and $0.80 \times 10^{9} / \mathrm{L}$, respectively. The most discriminative cut-points of the

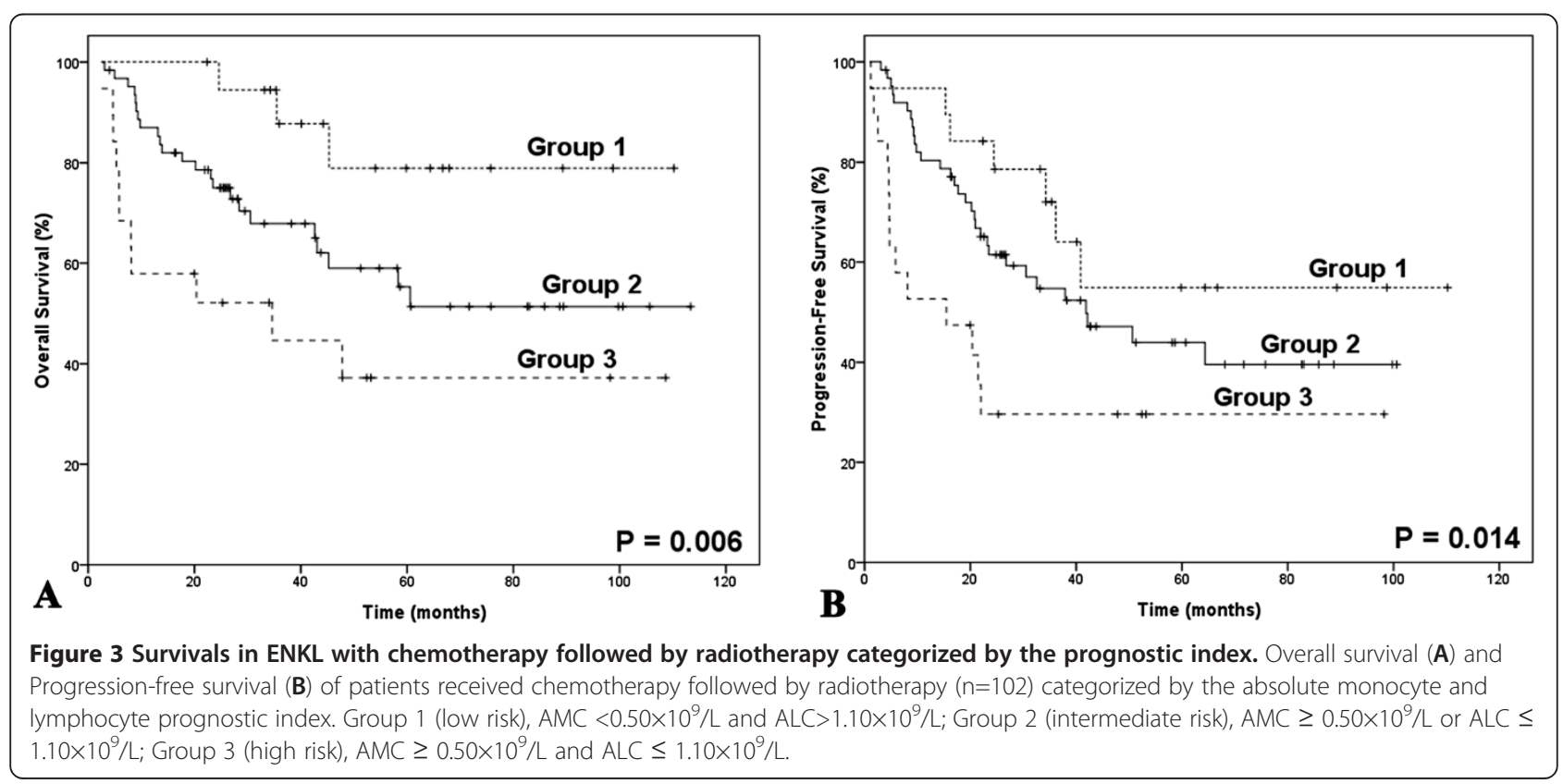




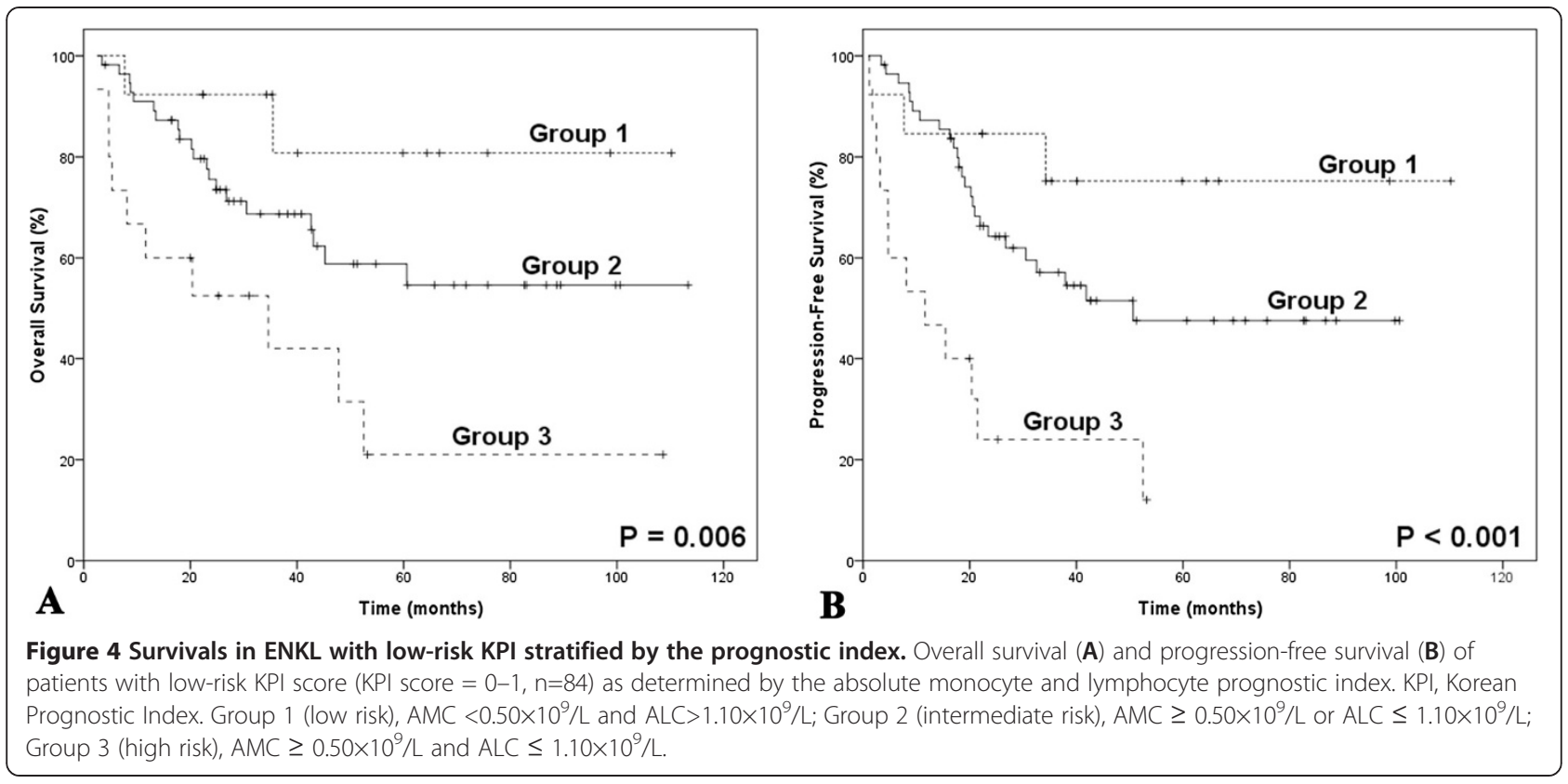

AMC was $0.495 \times 10^{9} / \mathrm{L}$ (area under the curve [AUC]: 0.630 , $95 \%$ confidence interval: $0.534-0.726, P=0.011$ ), as determined by receiver operating characteristics (ROC) analysis. Therefore, AMC $\geq 0.50 \times 10^{9} / \mathrm{L}$ which were close to the most discriminative cut-points, were selected as the optimal cut-off values. The most discriminative cut-points of the ALC were $1.145 \times 10^{9} / \mathrm{L}$ (AUC: $0.601,95 \%$ confidence interval: $0.512-0.690, P=0.027)$, as determined by ROC analysis. Therefore, ALC $\leq 1.10 \times 10^{9} / \mathrm{L}$, which was close to the most discriminative cut-point, was selected as the optimal cut-off value. Patients with high AMC at diagnosis tended to have poorer performance status $(\mathrm{P}=0.002)$ and $\mathrm{IPI}>1(\mathrm{P}=0.022)$.

\section{Survival and prognostic factors}

The initial treatment modalities were chemotherapy followed by radiotherapy $(n=102)$; chemotherapy alone $(\mathrm{n}=50)$; surgery followed by radiation $(\mathrm{n}=2)$; radiotherapy alone $(\mathrm{n}=4)$; and supportive care $(\mathrm{n}=5)$. The data on evaluation of treatment response to the initial therapy were available in 151 cases (92.6\%). Complete remission (CR) was observed in 71 patients (47.0\%). No statistical difference was found in the baseline clinical characteristics between patients with $A M C \geq 0.50 \times 10^{9} / \mathrm{L}$ and those with AMC $<0.50 \times 10^{9} / \mathrm{L}$.

The estimated overall survival (OS) and progression-free survival (PFS) at 5 years was $43.7 \%$ and $33.9 \%$, respectively. Patients with higher AMC level (AMC $\geq 0.50 \times 10^{9} / \mathrm{L}$, $\mathrm{n}=118$ ) seemed to have shorter OS and PFS (OS: $P=0.023$; PFS: $P=0.016$; Figure $1 \mathrm{~A}$ and $\mathrm{B})$. Univariate analysis of $\mathrm{AMC}$ as a continuous variable also showed
AMC to be related to inferior survival (OS: $P<0.001$; PFS: $P=0.049)$. As KPI and IPI are commonly used prognostic indexes for ENKL, they were included with AMC in multivariate analysis. As shown in Table 2 and Table 3, AMC retained their prognostic impact on OS and PFS in patients with ENKL, independent of IPI score. KPI score was not found to be an independent prognostic factor of survival in multivariate analysis.

\section{The AMC/ALC prognostic index identifies high-risk patients in ENKL}

Absolute lymphocyte count (ALC), as an indicator of immune status, was shown to be associated with OS and PFS in our previous study [19]. However, either AMC or ALC, as a single parameter, appeared to have limited ability to identify patients in the poor-risk category. Therefore, we combined the baseline AMC with the baseline ALC as dichotomized variables, to obtain a host immunity-related prognostic index of survival in patients with ENKL. Regarding the AMC/ALC prognostic index as a categorical variable, all 163 patients were stratified into the following three risk categories: group 1 (low risk), AMC $<0.50 \times 10^{9} / \mathrm{L}$ and ALC $>1.10 \times 10^{9} / \mathrm{L} ;$ group 2 (intermediate risk), AMC $\geq 0.50 \times 10^{9} / \mathrm{L}$ or ALC $\leq 1.10 \times 10^{9} / \mathrm{L}$; group 3 (high risk), AMC $\geq 0.50 \times 10^{9} / \mathrm{L}$ and ALC $\leq 1.10 \times 10^{9} / \mathrm{L}$. The associations between patients' clinical characteristics and AMC/ALC prognostic index were evaluated. Patients with high risk AMC/ALC index seemed to have a higher rate of $B$ symptoms $(P=0.005)$. The OS and PFS based on the AMC/ALC prognostic index for patients with ENKL are shown in Figure 2. Univariate analysis showed that the AMC/ALC index allowed the discrimination of the three 

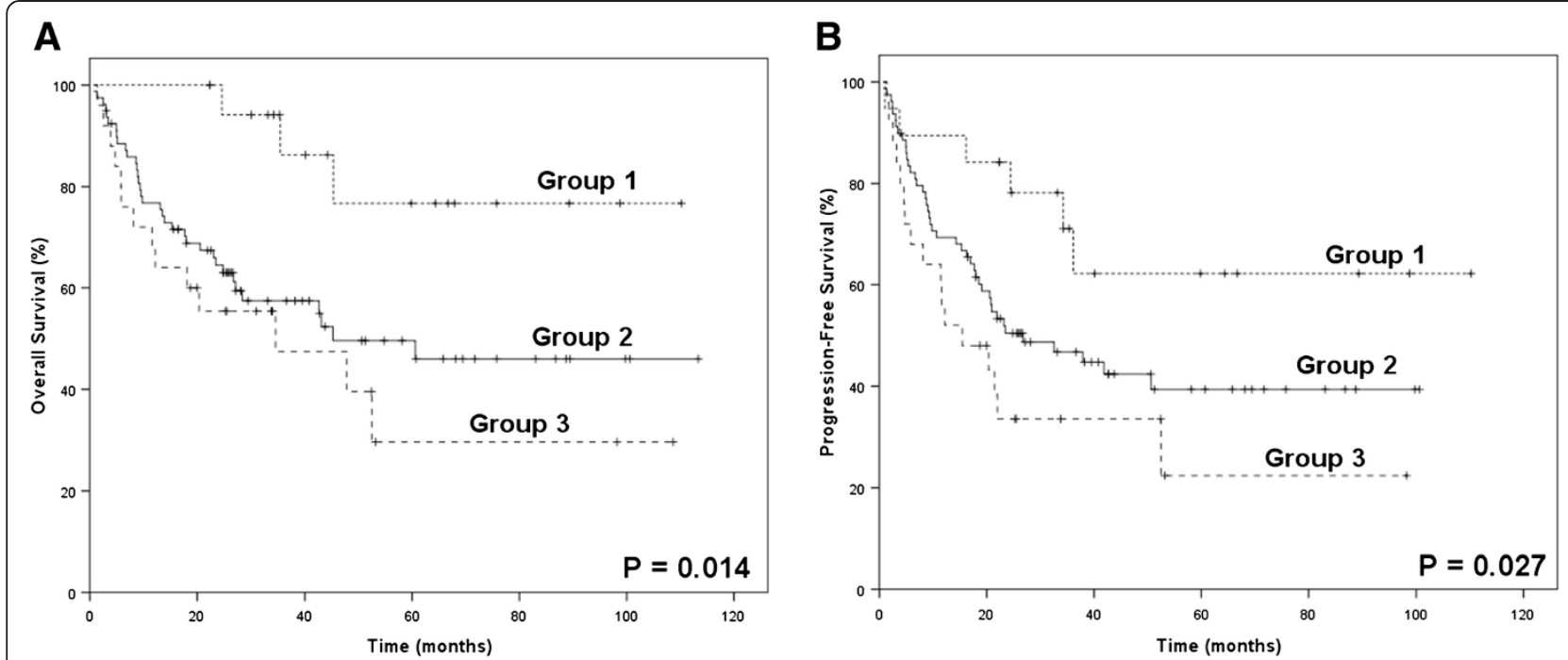

Figure 5 Survivals in ENKL with low-risk IPI stratified by the prognostic index. Overall survival (A) and progression-free survival (B) of patients with low-risk IPI score (IPI score $=0-1, n=125)$ as determined by the absolute monocyte and lymphocyte prognostic index. IPI, International Prognostic Index. Group 1 (low risk), $\mathrm{AMC}<0.50 \times 10^{9} / \mathrm{L}$ and $\mathrm{ALC}>1.10 \times 10^{9} / \mathrm{L}$; Group 2 (intermediate risk), $\mathrm{AMC} \geq 0.50 \times 10^{9} / \mathrm{L}$ or $\mathrm{ALC} \leq 1.10 \times 10^{9} / \mathrm{L}$; Group 3 (high risk), AMC $\geq 0.50 \times 10^{9} / \mathrm{L}$ and $\mathrm{ALC} \leq 1.10 \times 10^{9} / \mathrm{L}$.

risk groups with a 5 -year OS ranging from $74.2 \%$ to $23.2 \%$, $P=0.001$ and a 5 -year PFS varying from $54.0 \%$ to $17.5 \%$, $P=0.002$. For patients who received chemotherapy followed by radiotherapy (102 cases), the three AMC/ALC index categories identified patients with significantly different survivals (OS: $P=0.006$; PFS: $P=0.014$; Figure 3 ). Moreover, when applied to the patients with low-risk IPI score (IPI $=0-1)$ or low-risk KPI score (KPI $=0-1$ ), the AMC/ALC index identified significantly different prognostic categories in patients with low-risk KPI score (OS: $P=0.006$; PFS: $P<0.001$; Figure 4) and patients with lowrisk IPI score (OS: $P=0.014$; PFS: $P=0.027$; Figure 5). Further stratification by AMC/ALC index category identified 15 patients $(17.9 \%)$ in the low-risk KPI score category and 25 patients (20\%) in the low-risk IPI score category as high risk (5-year OS of $21.0 \%$ and $29.7 \%$, respectively).

\section{Discussion}

Epidemiologic studies show that immune deficiency increases the risk of NHL [30,31]. The incidence of NHL was much higher in immunosuppressed individuals than in non-immunosuppressed individuals [32,33]. Geneexpression signature studies in patients with B-cell NHL indicated that the myeloid-lineage cells in the tumor microenvironment influence the survival outcomes of patients with DLBCL and FL $[15,16]$. Monocytes were found to heavily infiltrate tumor samples from lymphoma patients, and this infiltration was found to be related to tumor invasion and immune response suppression in the animal model of lymphoma [15]. Furthermore, monocytes were recently found to promote the cell growth and survival in T-cell lymphomas and NK/T-cell lymphoma $[23,24]$. The predictive role of absolute monocyte count has been studied in B-cell NHL, as well as some solid tumors [25,26,34-36]. Limited data are available about the influence of monocytes on the survival of patients with ENKL. Hence, our study was carried out to evaluate the relevance of the peripheral blood monocyte count (a surrogate marker of the tumor microenvironment and host immunity) as a prognostic marker of survival in ENKL.

In this series, relatively elevated AMC at diagnosis (when treated as a continuous or dichotomized variable) was related to inferior prognosis. In multivariate analysis, AMC retained its prognostic impact on survival outcome in ENKL, and was independent of the conventional prognostic index. Evidence that AMC is an adverse prognostic factor in NHL was recently provided by Wilcox et al. in patients with DLBCL and FL [25,26]. AMC combined with IPI or Follicular Lymphoma International Prognostic Index (FLIPI) score helped to identify patients with poor prognosis. In patients with some solid neoplasms such as melanoma, renal cell carcinoma, and small cell lung cancer, elevated monocytes used as an immune parameter were also related to unfavorable survival [34-37]. Myeloid-derived cells (MDCs), including tumor-infiltrating monocytes and their progeny, were demonstrated to promote tumor angiogenesis and metastasis by suppressing the host immune response through regulation of macrophage cytokine production [38]. In T-cell NHL, many MDCs are found in the tumor microenvironment. When malignant $\mathrm{T}$ cells are co-cultured with monocytes, the proliferation and growth of tumor 
cells are increased. In contrast, when monocytes are depleted, malignant $T$ cell death is increased [23]. Similar phenomena are observed in NK/T-cell lymphoma. Monocytes promote the cell proliferation and growth of EBVpositive NK/T-cell lymphoma cells, as well as the EBVencoded latent membrance protein-1 (LMP-1) expression and interferon inducible protein-10 (IP-10) production. These functions of monocytes are mediated by cell contact dependent interaction via interleukin (IL)-15 [24]. Production by NK/T-cell lymphoma cells of IP-10 (a major chemoattractant of human monocytes) can increase monocyte infiltration of the tumor microenvironment [39-41]. Therefore, there is a positive feedback relationship between monocytes and lymphoma cells in the microenviroment of NK/T-cell lymphoma [24].

Lymphocyte count is another surrogate marker of immune homeostasis, and lymphopenia is regarded as an indicator of immunoincompetence [42]. Lymphopenia was an independent prognostic factor of adverse survival in our previous studies [19]. In the current study, our results showed that monocyte was also helpful to predict prognosis in ENKL. Therefore, we devised a simple prognostic index related to tumor microenvironment and host immune status that incorporates both AMC and ALC. This index was independent of conventional prognostic indices (such as KPI and IPI) and can be easily applied in clinical practice. The AMC/ALC index stratified patients with ENKL into three risk categories with significantly different survival outcomes. The current study and previous studies showed that the majority of patients with ENKL have no or one adverse IPI score or KPI score $[12,19]$. When superimposed on the IPI or KPI score, the AMC/ ALC index provides additional prognostic information. This novel index was able to identify about $20 \%$ of patients in the low-risk KPI or low-risk IPI score category as high risk (with an inferior 5-year OS of less than 30\%).

The current management of newly diagnosed ENKL patients was mainly based on the involvement sites (localized or disseminated disease). In this series, although most of the ENKL patients with localized disease underwent chemotherapy combined with radiation, some patients in this subgroup had unfavorable prognosis. The AML/ALC index was helpful to identify patients with poor survival outcomes. Maybe the combined treatment modality is insufficient to cure the high-risk patients. Several retrospective studies suggested that high-dose chemotherapy followed by autologous hematopoietic stem cell transplantation (HD-AHSCT) showed promising results for patients with disseminated ENKL [43-45]. It is interesting to investigate the efficacy of HD-AHSCT in the high-risk patients with localized disease in future studies. In this series, the underlying positive or negative biases during the therapy or selection of patients were inevitable, due to the limitation of its retrospective nature. Future prospective studies are warranted to validate our results.

\section{Conclusion}

In conclusion, the baseline monocyte count is helpful to predict prognosis in ENKL patients. The AMC/ALC prognostic index, incorporating variables associated with the tumor microenvironment and host immunity, may offer a better risk stratification for patients with ENKL, when superimposed on the IPI or KPI. This finding warrants confirmation in independent cohorts. Further investigation is required to achieve a better understanding of the mechanism underlying the relationship between immunology and prognosis in NK/T-cell lymphoma.

\section{Competing interests}

The authors have declared that no competing interests exist.

\section{Authors' contributions}

$J \mathrm{JH}$ designed the study, participated in the statistical analysis, and drafted the manuscript. YJL performed the statistical analysis and participated in the collection of the clinical data. YX, YW, WXW, YJZ, TYL, HQH and WQJ participated in the collection of the clinical data. ZML conceived of the study, and participated in its design and coordination and helped to draft the manuscript. All authors read and approved the final manuscript.

\section{Acknowledgements}

The authors thank the patients and their families and all the investigators, including the physicians, nurses, and laboratory technicians in this study.

\section{Funding}

This work was supported by National Natural Science Foundation of China (NO. 81071950), Fundamental Research Funds for the Central Universities (NO. 10ykpy36), National-Eleventh Five Technology Major Project (NO. 2008ZX09312-002, 2012ZX09301), and Research Award Funds for Outstanding Young Researchers in Sun Yat-Sen Cancer Center. The funders had no role in study design, data collection and analysis, decision to publish, or preparation of the manuscript.

Received: 13 December 2012 Accepted: 25 April 2013 Published: 3 May 2013

\section{References}

1. Jaccard A, Hermine O: Extranodal natural killer/T-cell lymphoma: advances in the management. Curr Opin Oncol 2011, 23:429-435.

2. Liang X, Graham DK: Natural killer cell neoplasms. Cancer 2008, 112:1425-1436.

3. Gill H, Liang RH, Tse E: Extranodal natural-killer/t-cell lymphoma, nasal type. Adv Hematol 2010, 201:627401.

4. Gualco G, Domeny-Duarte P, Chioato L, Barber G, Natkunam Y, Bacchi CE: Clinicopathologic and molecular features of 122 Brazilian cases of nodal and extranodal NK/T-cell lymphoma, nasal type, with EBV subtyping analysis. Am J Surg Pathol 2011, 35:1195-1203.

5. Yang QP, Zhang WY, Yu JB, Zhao S, Xu H, Wang WY, Bi CF, Zuo Z, Wang $X Q$, Huang J, Dai L, Liu WP: Subtype distribution of lymphomas in Southwest China: analysis of 6,382 cases using WHO classification in a single institution. Diagn Pathol 2011, 6:77.

6. Li ZM, Zhu YJ, Sun J, Xia Y, Huang JJ, Zou BY, Lin TY, Huang HQ, Jiang WQ: Serum beta2-microglobin is a predictor of prognosis in patients with upper aerodigestive tract NK/T-cell lymphoma. Ann Hematol 2012, 91:1265-1270.

7. Wang ZY, Li YX, Wang H, Wang WH, Jin J, Liu YP, Song YW, Wang SL, Liu $X F, Y u Z H$ : Unfavorable prognosis of elderly patients with early-stage extranodal nasal-type NK/T-cell lymphoma. Ann Oncol 2011, 22:390-396.

8. Huang JJ, Zhu YJ, Xia Y, Zhao W, Lin TY, Jiang WQ, Huang HQ, Li ZM: A novel prognostic model for extranodal natural killer/T-cell lymphoma. Med Oncol 2012, 29:2183-2190. 
9. de Leval L, Gaulard P: Pathology and biology of peripheral T-cell lymphomas. Histopathology 2011, 58:49-68.

10. Ham MF, Ko YH: Natural killer cell neoplasm: biology and pathology. Int J Hematol 2010, 92:681-689.

11. Li YX, Fang H, Liu QF, Lu J, Qi SN, Wang H, Jin J, Wang WH, Liu YP, Song YW, Wang SL, Liu XF, Feng XL, Yu ZH: Clinical features and treatment outcome of nasal-type NK/T-cell lymphoma of waldeyer ring. Blood 2008, 112:3057-3064.

12. Lee J, Suh C, Park YH, Ko YH, Bang SM, Lee JH, Lee DH, Huh J, Oh SY, Kwon HC, Kim HJ, Lee SI, Kim JH, Park J, Oh SJ, Kim K, Jung C, Park K, Kim WS: Extranodal natural killer T-cell lymphoma, nasal-type: a prognostic model from a retrospective multicenter study. J Clin Oncol 2006 24:612-618.

13. Lin $Y$, Gustafson MP, Bulur PA, Gastineau DA, Witzig TE, Dietz AB: Immunosuppressive CD14+HLA-DR(low)/- monocytes in B-cell non-Hodgkin lymphoma. Blood 2011, 117:872-881.

14. Tran H, Nourse J, Hall S, Green M, Griffiths L, Gandhi MK: Immunodeficiency-associated lymphomas. Blood Rev 2008, 22:261-281.

15. Lenz G, Wright G, Dave SS, Xiao W, Powell J, Zhao H, Xu W, Tan B, Goldschmidt N, lqbal J, et al: Stromal gene signatures in large-B-cell lymphomas. N Engl J Med 2008, 359:2313-2323.

16. Dave SS, Wright G, Tan B, Rosenwald A, Gascoyne RD, Chan WC, Fisher RI, Braziel RM, Rimsza LM, Grogan TM, et al: Prediction of survival in follicular lymphoma based on molecular features of tumor-infiltrating immune cells. N Engl J Med 2004, 351:2159-2169.

17. Steidl C, Gascoyne RD: The molecular pathogenesis of primary mediastinal large B-cell lymphoma. Blood 2011, 118:2659-2669.

18. De Angulo G, Yuen C, Palla SL, Anderson PM, Zweidler-McKay PA: Absolute lymphocyte count is a novel prognostic indicator in ALL and AML: implications for risk stratification and future studies. Cancer 2008, 112:407-415.

19. Huang JJ, Jiang WQ, Lin TY, Huang Y, Xu RH, Huang HQ, Li ZM: Absolute lymphocyte count is a novel prognostic indicator in extranodal natural killer/T-cell lymphoma, nasal type. Ann Oncol 2011, 22:149-155.

20. Kim DH, Baek JH, Chae YS, Kim YK, Kim HJ, Park YH, Song HS, Chung JS, Hyun MS, Sohn SK: Absolute lymphocyte counts predicts response to chemotherapy and survival in diffuse large B-cell lymphoma. Leukemia 2007, 21:2227-2230.

21. Kim YR, Kim JS, Kim SJ, Jung HA, Kim SJ, Kim WS, Lee HW, Eom HS, Jeong SH, Park JS, Cheong JW, Min YH: Lymphopenia is an important prognostic factor in peripheral T-cell lymphoma (NOS) treated with anthracyclinecontaining chemotherapy. J Hematol Oncol 2011, 4:34

22. Porrata LF, Ristow K, Witzig TE, Tuinistra N, Habermann TM, Inwards DJ, Ansell SM, Micallef IN, Johnston PB, Markovic SN: Absolute lymphocyte count predicts therapeutic efficacy and survival at the time of radioimmunotherapy in patients with relapsed follicular lymphomas. Leukemia 2007, 21:2554-2556.

23. Wilcox RA, Wada DA, Ziesmer SC, Elsawa SF, Comfere NI, Dietz AB, Novak AJ, Witzig TE, Feldman AL, Pittelkow MR, Ansell SM: Monocytes promote tumor cell survival in T-cell lymphoproliferative disorders and are impaired in their ability to differentiate into mature dendritic cells. Blood 2009, 114:2936-2944

24. Ishii H, Takahara M, Nagato T, Kis LL, Nagy N, Kishibe K, Harabuchi Y, Klein E: Monocytes enhance cell proliferation and LMP1 expression of nasal natural killer/T-cell lymphoma cells by cell contact-dependent interaction through membrane-bound IL-15. Int J Cancer 2012, 130:48-58.

25. Wilcox RA, Ristow K, Habermann TM, Inwards DJ, Micallef IN, Johnston PB, Colgan JP, Nowakowski GS, Ansell SM, Witzig TE, Markovic SN, Porrata L: The absolute monocyte and lymphocyte prognostic score predicts survival and identifies high-risk patients in diffuse large-B-cell lymphoma. Leukemia 2011, 25:1502-1509.

26. Wilcox RA, Ristow K, Habermann TM, Inwards DJ, Micallef IN, Johnston PB, Colgan JP, Nowakowski GS, Ansell SM, Witzig TE, Markovic SN, Porrata L: The absolute monocyte count is associated with overall survival in patients newly diagnosed with follicular lymphoma. Leuk Lymphoma 2012, 53:575-580.

27. Kim TM, Heo DS: Extranodal NK/T-cell lymphoma, nasal type: new staging system and treatment strategies. Cancer Sci 2009, 100:2242-2248.

28. Sehn LH, Berry B, Chhanabhai M, Fitzgerald C, Gill K, Hoskins P, Klasa R Savage KJ, Shenkier T, Sutherland J, Gascoyne RD, Connors JM: The revised international prognostic index (R-IPI) is a better predictor of outcome than the standard IPI for patients with diffuse large B-cell lymphoma treated with R-CHOP. Blood 2007, 109:1857-1861.

29. Cheson BD, Pfistner B, Juweid ME, Gascoyne RD, Specht L, Horning SJ, Coiffier B, Fisher RI, Hagenbeek A, Zucca E, Rosen ST, Stroobants S, Lister TA, Hoppe RT, Dreyling M, Tobinai K, Vose JM, Connors JM, Federico M, DiehI V, International Harmonization Project on Lymphoma: Revised response criteria for malignant lymphoma. J Clin Oncol 2007, 25:579-586.

30. Grulich $A E$, Vajdic CM: The epidemiology of non-Hodgkin lymphoma. Pathology 2005, 37:409-419.

31. Smedby KE, Hjalgrim H: Epidemiology and etiology of mantle cell lymphoma and other non-Hodgkin lymphoma subtypes. Semin Cance Biol 2011, 21:293-298.

32. Jacobson CA, LaCasce AS: Lymphoma: risk and response after solid organ transplant. Oncology (Williston Park) 2011, 24:936-944.

33. Morton LM, Wang SS, Cozen W, Linet MS, Chatterjee N, Davis S, Severson RK, Colt JS, Vasef MA, Rothman N, Blair A, Bernstein L, Cross AJ, De Roos AJ, Engels EA, Hein DW, Hill DA, Kelemen LE, Lim U, Lynch CF, Schenk M, Wacholder S, Ward MH, Hoar Zahm S, Chanock SJ, Cerhan JR, Hartge P: Etiologic heterogeneity among non-Hodgkin lymphoma subtypes. Blood 2008, 112:5150-5160.

34. Schmidt H, Bastholt L, Geertsen P, Christensen IJ, Larsen S, Gehl J, von der Maase $\mathrm{H}$ : Elevated neutrophil and monocyte counts in peripheral blood are associated with poor survival in patients with metastatic melanoma: a prognostic model. Br J Cancer 2005, 93:273-278.

35. Lopez-Gonzalez JS, Avila-Moreno F, Prado-Garcia H, Aguilar-Cazares D, Mandoki JJ, Meneses-Flores M: Lung carcinomas decrease the number of monocytes/macrophages (CD14+ cells) that produce TNF-alpha. Clin Immunol 2007, 122:323-329.

36. Hase S, Weinitschke K, Fischer K, Fornara P, Hoda R, Unverzagt S, Seliger B, Riemann D: Monitoring peri-operative immune suppression in renal cancer patients. Oncol Rep 2011, 25:1455-1464.

37. Donskov F, von der Maase $\mathrm{H}$ : Impact of immune parameters on long-term survival in metastatic renal cell carcinoma. J Clin Oncol 2006, 24:1997-2005

38. Sinha P, Clements VK, Bunt SK, Albelda SM, Ostrand-Rosenberg S: Cross-talk between myeloid-derived suppressor cells and macrophages subverts tumor immunity toward a type 2 response. J Immunol 2007, 179:977-983.

39. Miyauchi K, Urano E, Yoshiyama H, Komano J: Cytokine signatures of transformed B cells with distinct Epstein-Barr virus latencies as a potential diagnostic tool for B cell lymphoma. Cancer Sci 2011, 102:1236-1241.

40. Moriai S, Takahara M, Ogino T, Nagato T, Kishibe K, Ishii H, Katayama A, Shimizu N, Harabuchi Y: Production of interferon-\{gamma\}-inducible protein-10 and its role as an autocrine invasion factor in nasal natural killer/T-cell lymphoma cells. Clin Cancer Res 2009, 15:6771-6779.

41. Nourse JP, Jones K, Gandhi MK: Epstein-Barr virus-related post-transplant lymphoproliferative disorders: pathogenetic insights for targeted therapy. Am J Transplant 2011, 11:888-895.

42. Datta S, Sarvetnick N: Lymphocyte proliferation in immune-mediated diseases. Trends Immunol 2009, 30:430-438.

43. Murashige N, Kami M, Kishi Y, Kim SW, Takeuchi M, Matsue K, Kanda Y, Hirokawa M, Kawabata Y, Matsumura T, Kusumi E, Hirabayashi N, Nagafuji K, Suzuki R, Takeuchi K, Oshimi K: Allogeneic haematopoietic stem cell transplantation as a promising treatment for natural killer-cell neoplasms. Br J Haematol 2005, 130:561-567.

44. Suzuki R, Suzumiya J, Nakamura S, Kagami Y, Kameoka Jl, Sakai C, Mukai H, Takenaka K, Yoshino T, Tsuzuki T, Sugimori H, Kawa K, Kodera Y, Oshimi K, NK-cell Tumor Study Group: Hematopoietic stem cell transplantation for natural killer-cell lineage neoplasms. Bone Marrow Transplant 2006, 37:425-431.

45. Lee J, Au WY, Park MJ, Suzumiya J, Nakamura S, Kameoka J, Sakai C, Oshimi K, Kwong YL, Liang $\mathrm{R}$, Yiu H, Wong $\mathrm{KH}$, Cheng HC, Ryoo BY, Suh $\mathrm{C}$, Ko YH, Kim K, Lee JW, Kim WS, Suzuki R: Autologous hematopoietic stem cell transplantation in extranodal natural killer/T cell lymphoma: a multinational, multicenter, matched controlled study. Biol Blood Marrow Transplant 2008, 14:1356-1364.

doi:10.1186/1471-2407-13-222

Cite this article as: Huang et al:: Prognostic significance of peripheral monocyte count in patients with extranodal natural

killer/T-cell lymphoma. BMC Cancer 2013 13:222 